\title{
Policy Issues Associated \\ With Analyzing Outcomes of Care
}

\author{
Katherine R. Jones, Bonnie Mowinski Jennings, Patricia Moritz, Mae Taylor Moss
}

\begin{abstract}
Policy questions associated with the conduct of outcomes studies are addressed and outcomes management and outcomes research are differentiated. Multiple outcomes initiatives are being undertaken in the United States, from the institutional to national and international levels. Nurses have had limited involvement, thus far-although the array of outcomes being examined is considerable. Members of an American Academy of Nursing expert panel on quality health care discuss the environmental context and multiple focuses of outcomes analysis. They provide an overview of current activities, present the challenges confronting nursing in its pursuit of a quality assessment agenda, and make recommendations for increasing nurses' participation in quality initiatives.
\end{abstract}

Image: Journal of Nursing Scholarship, 1997; 29(3), 261-267. (C1997, Sigma Theta Tau International.

IKeywords: health policy; outcome evaluation;

identify outcomes; outcome assessment management]

nalyzing the outcomes of care is essential for guiding informed decision making in health care. In the United States, multiple initiatives attest to the growing interest in outcomes. Schlenker (1996) offered five compelling reasons to analyze outcomes: (a) payers are demanding information about the results of care delivery; (b) outcomes are an integral part of accreditation; (c) consumers have a right to know about outcomes; (d) regulatory agencies demand information about outcomes; and (e) outcomes represent the basic reason for providing care. Thus, members of the American Academy of Nursing's (AAN) Expert Panel on Health Care Quality are examining the policy issues associated with outcomes research and outcomes management.

\section{Background}

With Margaret Sovie as chairperson, the Expert Panel on Quality Health Care was designated in 1994 for the purpose of exerting leadership at national and state levels on quality assessment and measurement in health care. An overriding focus of the panel has been to ensure that quality indicators identified as critical to evaluating the outcomes of care reflect contributions of nursing. The panel first convened at the Academy's annual meeting in 1994 and produced a preliminary model of quality outcomes subsequently named the Quality Health Outcomes Model (Q-HOM). Pamela Mitchell and Janet Heinrich spearheaded the submission of a request for funding from the Agency for Health Care Policy and Research (AHCPR) in support of an interdisciplinary conference on outcome measures. Simultaneously, a consultative role was initiated with the American Nurses' Association (ANA) as it embarked on the Nursing Report Card initiative.
At the second formal meeting of the Expert Panel at the Academy's 1995 annual meeting, the following priorities were set:

1. Revise and refine the Quality Health Outcomes Model.

2. Work toward consensus in interdisciplinary groups and nursing communities on an initial set of health care outcomes that are sensitive to nursing care.

3. Achieve nursing's inclusion in the many national, regional, and state forums shaping health policy related to the quality and cost of health care.

4. Continue collaboration with the ANA on its Report Card project.

5. Promote the ongoing development of clinical and organizational outcomes research as an integral component of nursing science.

6. Convene the AHCPR-funded national invitational conference on outcome indicators and care delivery systems.

Essential to these efforts has been the need to better define the field of outcomes analysis. In particular, panel members expressed concern that outcomes analysis may not be viewed by

Katherine R. Jones, RN, PhD, FAAN, Rho, is Interim Division Director and Associate Professor, University of Michigan, Ann Arbor, MI. Bonnie Mowinski Jennings, RN, DNSc, FAAN, Alpha Eta, is Colonel, U.S. Army Nurse Corps, Madigan Army Medical Center, Tacoma, WA. Patricia Moritz, RN, PhD, FAAN, Alpha Kappa, is Acting Associate Dean for Research; Director, Center for Nursing Research; Associate Professor, University of Colorado, Denver, CO. Mae Taylor Moss, RN, MS, MSN, FAAN, Eta Phi, is President, Moss Management Consultants International, Houston, TX. The ideas expressed in this paper represent those of the authors. They may or may not reflect the position of the Academy of Nursing, the ANA, or the Expert Panel on Health Care Quality. Neither do they necessarily reflect the views of the U.S. Department of Defense, Department of the Army, or the Army Medical Department. Correspondence to Dr. Jones, Associate Professor and Interim Division Director, University of Michigan School of Nursing, $400 \mathrm{~N}$. Ingalls Street, Ann Arbor, Ml 48109-0483.

Accepted for publication April 16, 1997. 
some as sufficiently scientific to achieve equality with other areas of nursing inquiry. Although commonly employed, the term outcomes research "has come to be used so sweepingly ... that it has become problematic" (U.S. Congress, 1994, p. 123). The term outcomes analysis is used here to refer to conducting outcome studies at all levels in naturally occurring situations.

\section{Defining Outcomes}

Donabedian (1985) defined outcomes as "those changes, either favorable or adverse, in the actual or potential health status of persons, groups, or communities, that can be attributed to prior or concurrent care" (p. 256). This definition allows a broad range of outcome variables to be considered, and includes both clinical and cost outcomes of care. A major characteristic of outcomes studies is that they focus on the effectiveness of care, or the results of services delivered by a typical clinician in a typical setting. This is in contrast to efficacy studies, characterized by randomized clinical trials (RCTs), in which treatments are administered by experts through tightly specified study protocols in closely monitored practice settings (Iezzoni, 1994). Effectiveness studies are intended to answer questions relating to the relative merits of comparative clinical practices (Iezzoni, 1994), as well to assess the effect of organizational and system changes on patients, families, or communities.

Outcomes studies reflect individual patient preferences and decisionmaking, as well as family influences, on the outcomes of care. Ellwood (1988) described outcomes management as a way to help patients, payers, and providers make rational medical-care-related choices based on better insight into the effect of these choices on a patient's life. Iezzoni (1994) points out that the Clinton Health Security Act specifically called for research into the outcomes of health care services to determine which treatments work best for which conditions. The possibility that outcomes information will be used to produce report cards comparing the performance of providers is a current reality.

Typical questions addressed by outcomes studies include: Which discharge preparation protocol most enhances the patient's capability for self-care after hospital discharge? Which clinical interventions are associated with the greatest degree of symptom relief? How the change in staff skill mix affected patient satisfaction? Is there a difference across a system's caredelivery sites in clients' health promoting activities? What is the burden of care imposed on families as a result of early hospital discharge? Does sharing a critical pathway with the patient and family lead to improved clinical outcomes?

Questions like these can be addressed through time-sensitive outcomes management programs or through more systematic and time-intensive outcomes research projects. Both avenues of inquiry are used to inform practice and the public.

\section{Environmental Context of Outcomes Analysis}

Significant changes in health care support the need to analyze the outcomes of care. Change is rapid and as typified by managed care-includes new modes of risk-sharing, movement to community-based care, organizational restructuring, and the use of clinical guidelines.
Managed Care Penetration. Although definitions of managed care vary, the percentage of local and regional penetration of managed care is expanding in the United States while the amount of care covered in the indemnity insurance and fee-for-service sectors is rapidly shrinking. Managed care pertains both to financing and care delivery (Zelman, 1996). Managed-care strategies applied by different health care plans vary. They include pre-certification requirements for admissions and specialty care, caps on the number of hospital days and number of home health visits, limited or restrictive drug formularies, aggressive case management, and disease management. Many managed care plans are budgeted based on established capitated rates for their enrolled populations. Managed care-plan terminology is described in Table 1. Each entity establishes a variety of financial incentives to providers and enrollees to reduce health service use and to promote the most cost-effective use of resources.

Risk-sharing. In the past, insurance companies assumed the risks associated with illness and health services utilization. The result was manifested in perpetually escalating health insurance premiums. Now, providers and consumers are required to share these risks. Providers must negotiate contracts with health plans on the basis of "covered lives" (number of enrollees in the health plan) and capitated payment rates. Costs that are greater than expected can no longer be passed on to the purchasers of health care. Patients who select providers not on a health plan's approved list elect to incur out-of-pocket costs.

Table 1: Managed Care Abbreviations

\begin{tabular}{ll}
\hline ADS & Alternative Delivery System \\
AMCRA & American Managed Care and Review Association \\
ASC & Ambulatory Surgery Center \\
CAP & Capitation Payment \\
CMS & Care Management System \\
CM;CMS & Case Management; Case Management System \\
CMP & Competitive Medical Plan \\
EPO & Exclusive Provider Organization \\
HMO & Health Maintenance Organization \\
HCPP & Health Care Prepayment Plan \\
HIPC & Health Insurance Purchasing Cooperative or Coalition \\
IOS & Integrated Delivery System \\
IHO & Integrated Health Organization \\
IPA & Individual or Independent Practice Association \\
MCO & Managed Care Organization \\
MeSH & Medical Staff-Hospital Organization \\
MSO & Management or Niedical Services Organization \\
ODS & Organized Delivery System \\
PHO & Physician-Hospital Organization \\
PCCM & Primary Care Case Manager \\
PCC & Physician-sponsored Coordinated Care Organization \\
PMC & Physician Management Corporation \\
PMPM:PMPY & Per Member Per Month; Per Member Per Year \\
POS & Point of Service Plan \\
PPO & Preferred Provider Organization \\
PSN & Provider Sponsored Network \\
PSO & Provider Sponsored Service Organization \\
URO & Utilization Review Organization \\
UM & Utilization Management \\
\hline & \\
\hline
\end{tabular}


Community-based Care. Care provided in the inpatient setting is more intense and is delivered over a shorter duration in the 1990s than in the past. To accommodate this change, a large portion of care is delivered in communities and homes--not hospitals. Patients are moving through the various sites of care delivery rapidly, necessitating a shift in focus from traditional episodic care to innovative transitional care and to communitylevel delivery. Integrated delivery systems and networks of care are evolving to promote seamless, cost-effective care. Point-ofentry information systems are needed for creating a patient record that is also seamless across care-delivery sites.

Organizational Revamping. The need to develop more costeffective ways of providing patient care services has lead to many initiatives to change the way work is organized and care is delivered. These initiatives are labelled work re-engineering, restructuring, and redesign. Work environment changes introduced by these initiatives include cross-training of nursing personnel to achieve the versatility of multiskilled workers, decentralizing services to patient care units, increasing the use of unlicensed personnel, and creating automated documentation systems.

Clinical guidelines and pathways. In response to the welldocumented existence of significant variations in practice, efforts have been made to standardize care delivery for specific patient populations. By identifying the "best practices" for particular procedures and diagnoses, it is believed that the costs of care can be reduced without compromising the quality of clinical outcomes.

\section{Quality Initiatives}

The size and magnitude of changes in contemporary health care concern many, especially the providers of care, who question the effect these initiatives have on quality. Although most initiatives are couched in terms of reducing cost while preserving quality, cost-management often appears to be uppermost. Thus, there is renewed interest in measuring the outcomes of care, including clinical outcomes beyond mortality and morbidity, such as patient-reported health status and patient satisfaction (Lohr, 1988).

Many formal initiatives have been undertaken in response to this increasing interest. An overview of several major initiatives for measuring quality of care follows.

HEDIS. The Health Plan Employer Data and Information Set (HEDIS) was developed by the National Committee for Quality Assurance (NCQA). About half the HMOs in the United States have been reviewed in NCQA's accreditation process, although HEDIS is an independent, voluntary, complementary activity to NCQA's accreditation (Medical Outcomes Trust [MOT], 1996a). The original intent of HEDIS was to help business executives choose where to purchase health care for employees. More recently, HEDIS has been targeted to other purchasers and to consumers as greater numbers of health plans generate report cards based on HEDIS data (MOT, 1996b).

HEDIS 3.0 was released in July 1996. The eight areas in which HEDIS provides information are: effectiveness of care, access or availability of care, satisfaction with care, health plan stability, use of services, cost of care, informed health care choices, and health plan descriptive information. The updated version includes 75 standardized measures that must be reported by health plans: Another 30 measures are being evaluated. A significant addition is The Health of Seniors measure, which is essentially the SF-36 Health Status Survey applied to individuals over age 65 (MOT, 1996a). NCQA continues to develop measures for future versions of HEDIS, and they "have in mind a set of individuals who will work with us to move performance measures forward in key areas" (MOT,1996a, p1.). Nurse's involvement thus far has been limited to reviewing proposed measures.

FACCT. Perhaps less well known is the Foundation for Accountability (FACCT). Incorporated in 1995, FACCT is a nonprofit organization for helping consumers get information to make better decisions about health care. To accomplish this, FACCT endorses performance measures using specific criteria for approval; advocates adoption of FACCT measures with accrediting, certification, and licensing organizations; business and local communities; and consumer organizations; and helps consumers use FACCT measures (MOT, 1996a). As of Spring 1997, FACCT had endorsed quality measurement sets for asthma, breast cancer, diabetes, health risks, health status for the elderly, major depressive disorder, and health plan satisfaction (MOT, 1997). FACCT is now implementing these measures in selected markets. In December 1996, JCAHO announced its support of the first set of FACCT measures and the Health Care Financing Administration (HCFA) awarded the RAND Corporation a contract to begin using FACCT measures in several markets (MOT, 1997). Other purchasers are expected to ask health organizations to begin collecting data using FACCT measures (MOT, 199\%).

MOT and HOI. The third initiative is found in the Medical Outcomes Trust (MOT) and the Health Outcomes Institute (HOI). These organizations also have a primary interest in developing and reviewing standardized instruments for assessing quality, but focus specifically on Patient-Based Assessments (PBAs). The MOT has developed, refined, and promulgated tools to measure patient's functional status and well-being (the SF-36 and the SF-12) as well as patient satisfaction. The HOI develops and distributes condition-specific outcomes assessment forms. Generic measures of patient outcomes, which can be used across many settings and populations (Ware \& Sherbourne, 1992), are often supplemented with condition-specific outcome measures, such as symptom checklists. The shift from common and convenient outcome measures such as morbidity and mortality, to more relevant but less easy to measure indicators such as quality of life, symptom relief, and return to work, reflects the concerns of patients.

JCAHO. The Joint Commission has called for benchmarking, outcome assessment, and performance measurement in care delivery. In the late 1980 s, JCAHO began efforts to create a data-driven monitoring and feedback system within the context of continuous quality improvement (JCAHO, 1990). The latest JCAHO initiative is ORYX, which integrates performance measures into accreditation. In 1997, it requires that healthcare organizations select two clinical performance measures that relate to at least $20 \%$ of an organization's patient population. 
The number of measures will increase by two per year over the next 4 years, and the proportion of the patient population addressed will increase by $20 \%$ per year over the same period. Functional status and patient satisfaction measures probably will be included in the measures to be selected by organizations. A Type I recommendation will result if an organization fails to enroll in one of 60 performance measurement systems (JCAHO, 1997).

$I O M$. The recently released report from the Institute of Medicine (IOM) on nurse staffing and quality care (IOM, 1996) was directed by legislative mandate in 1994 in response to concerns about dramatic changes in hospitals such as restructuring, merging, and consolidation. IOM evaluators explored quality of care in hospitals and nursing homes, the relationship of quality of care and patient outcomes to nurse staffing levels and mix of nursing personnel, and ratios of nursing personnel to patients. The findings from this report are significant in that little empirical evidence was available to determine whether "hospital quality of care is being adversely affected by hospital restructuring and changes in the staffing patterns of nursing personnel" (IOM, 1996, p. 9). Little systematic evaluation of patient outcomes was also noted. The evaluators recommended conducting studies to examine the effect of changes in organizational design on patient outcomes, patient satisfaction, and nursing personnel. They also recommended developing performance and outcome measures that are sensitive to nursing interventions (IOM, 1996).

The IOM recently launched a Special Initiative on Health Care Quality - a 3-year effort to improve health care quality in the United States developed in response to changes in the health care system that appear to be cost-driven. Major goals are to (a) evaluate quality assessment and improvement tools; (b) promote appropriate application of these tools; (c) inform consumers, policymakers, providers, and others of key opportunities and obstacles for achieving better health outcomes; and (d) provide information and tools that enable better decisions and choices about health care (Shine, 1996). Individual studies will be carried out; a National Roundtable on Health Care Quality and a Managed Care Panel will be convened; and a coordinating committee will issue recommendations (Shine, 1996). A review of the membership of the roundtable reveals no nurses. The managed-care panel has one RN member.

Advisory Commission on Consumer Protection and Quality in the Health Care Industry. President Clinton recently appointed this advisory committee to develop a "Consumer Bill of Rights" that will promote and assure patient protections and health care quality. The 32-member Commission will review changes in health care financing and delivery systems and make recommendations about how best to preserve and improve quality of health care. It will conduct public meetings to collect and evaluate information on quality, consumer protection, and access. The Commission is cochaired by the Secretary of Health and Human Services and the Secretary of Labor. Its broad-based representation includes consumers, businesses, health care providers, insurers, quality experts, and financing experts. Three nurses are on this national commission. The final report is due March 1998.

\section{Table 2: Nursing Report Cand for Acute Care Settings-} Nursing's Quality Indicators

\author{
Outcome Indicators \\ Patient Satisfaction with Care \\ Nursing Care \\ Pain Management \\ Patient Education \\ Patient-Injury Rate \\ Nosocomial Infection Rate \\ Process Indicators \\ Maintenance of Skin Integrity \\ Nursing Staff Satisfaction \\ Structure Indicators \\ Mix of RNs, LPNs, and Unlicensed Staff \\ Total Nursing Care Hours Worked Per Patient
}

ANA Report Card Initiative. The ANA developed its report card in phases (ANA, 1995). In the first phase, based on an extensive literature review, 71 indicators were proposed as having a conceptual link to nursing. These were reduced to 21 and finally to 10 . In phase two, efforts were directed to developing common definitions for the 10 indicators. Interviews were held at various hospitals in the United States to establish agreed-upon definitions and ensure uniformity of the indicators. Currently, two state nurses' associations (Arizona and California) are conducting research projects to evaluate the feasibility of collecting data on the selected nursing indicators. The California Nursing Outcomes Coalition Database Project (CalNOC) is a collaborative effort to establish a statewide nursing quality outcomes database. One of the many CalNOC goals is to develop and implement a master plan to deliver a continuing education curriculum based on the State Nurses Association Nursing Quality Report Card Outcomes. As shown in Table 2, the 10 nursing report card indicators are in three categories: structure, process, and outcome. In this typology, level of nurse satisfaction is thought to affect achievement of specific patient outcomes and is classified as a process variable.

\section{Evolution of Outcomes Movement}

The significance of the current healthcare environmental context in the United States is best understood by an understanding of the historical evolution of the study of patient outcomes. Interest in health care outcomes surfaced in the 1980s as a result of Wennberg's analysis of variations in medical practice (Wennberg, 1984; 1986). Significant differences in treatment approaches for patients with similar conditions were found to be related to geographic location.

By the 1990s, examining outcomes moved beyond the conventional, traditional research paradigm. A recent JCAHO publication describes the division in health care between outcomes research and what it calls operations (JCAHO, 1994) or outcomes management. Research activity is directed toward discovering and disseminating new knowledge, and involves 
standardized methods for design, measurement, data collection, and data analysis (JCAHO, 1994). Research projects are limited in scope and duration, directed toward hypothesis testing, conducted under controlled conditions, and use precise criteria for subject inclusion and treatment protocols (JCAHO, 1994). Operations, on the other hand, are core activities involved in daily management.

As an outcomes management program evolves within an institution, it incorporates aspects of research and operations. Research provides the methodologic foundation, while operations call for continuous monitoring of routinely delivered care; exploratory, descriptive, and predictive data-analytic techniques; and a shift toward an empirical basis for routine clinical decision making (JCAHO, 1994). The comparison is made between outcomes management and industrial research and development, which is research in support of operations.

\section{Focus of Outcomes Analysis}

Outcomes studies are required to provide objective evaluation of many long-standing, traditional practices. Whether for insurers, Congress, health care executives, clinicians, patients, or families - a literature of "real world" findings can be developed from evaluating outcomes to support decision making (Bryan-Brown \& Dracup, 1996; Wojner, 1996). Assessing the outcomes of care can also be used to inform policy.

The need to scrutinize outcomes is underscored by the paucity of available knowledge regarding the effect of new care delivery models on outcomes. Subjective reporting of untoward events by telephone hotlines or staff nurses' anecdotes are not acceptable alternatives or substitutes for the systematic measurement of outcomes. Although the rush to legislate minimal staffing and minimal lengths of hospital stay is well intentioned, insufficient evidence exists for policy decision making. As noted, the IOM (1996) did not document a decline in the quality of care for hospitalized patients as a result of restructuring. In an editorial, Anderson (1996) laments that nursing has yet to produce the data that are needed to document its effect.

The lack of valid data also applies to various other reportcard initiatives being pursued. The U.S. General Accounting Office (GAO) (1994) identified the following concerning reportcard approaches to quality of care (a) evaluative studies have not been conducted to determine the report cards' validity or reliability; (b) information sources may have been inaccurate or misleading; (c) selected indicators may not adequately measure quality; and (d) verification mechanisms have not been in place to ensure accuracy of reported results. These problems need to be addressed by the ANA as it proceeds with development of its Nursing Report Card.

A debate revolves around discipline-specific and interdisciplinary outcomes as the focus of nursing outcomes studies. Some are adamant that nursing interventions and nursesensitive outcomes are the only appropriate focus for nursing studies, regardless of other interventions and outcomes that might be relevant. Others point out that care is increasingly delivered by teams of caregivers and selected outcomes are relevant to a number of disciplines. The challenge for nurse researchers is to un-bundle nursing contributions from interdisciplinary outcomes. Brooten and Naylor (1995) state that nurses do not care for patients in isolation and patients do not exist in isolation. Thus, while some outcomes may be highly influenced in a given context by nursing, these same outcomes may be affected more by other disciplines or family caregivers in other settings (Brooten \& Naylor, 1995).

An important step in specifying outcome indicators occurred at the invitational, interdisciplinary conference, Outcomes Measurement and Care Delivery Systems, convened in June 1996. The framework for the conference was from the Quality Health Outcomes Model, which proposed these five indicators: functional, social, psychological, physical, and physiologic aspects of patient experiences during health care encounters (Mitchell, 1996). These indicators were proposed because they are expected to be sensitive to health care interventions across the spectrum of care delivery. Conference participants reviewed the research base for each indicator, examined the relationship between outcome indicators and organizational factors, considered the indicators for further measurement development, and recommended areas for additional development. Specific indicators recommended were: achievement of appropriate selfcare, demonstration of health promoting behaviors, healthrelated quality of life, patient perceptions of being well cared for, symptom management, mortality and morbidity, and cost (Mitchell, 1996). The first five indicators are from the Q-HOM. Cost was added because of its importance.

\section{Challenges}

\section{Increasing Nursing's Involvement in Quality Initiatives}

Outcomes problems continue to be tackled and decided without nurses' participation or advice. Nurses appear to have been excluded from many national initiatives-whether by intention or oversight. Nurse visibility must be increased. The development of standardized nomenclatures is one way to help include nursing data elements in large databases.

Nurses should be involved when decisions concerning outcomes of health care delivery take place. Nurses should be partners in formulating questions, creating analysis plans, gathering data, and developing recommendations based upon findings from outcome studies. The exclusion of nurses might result in serious deficiencies in the analyses. For example, analysts for the Medical Outcomes Study examined the influence of multiple physician variables on patient outcomes, yet did not examine the effect of nurse staffing or level of nurses' preparation on outcomes. The challenge is for nurses to gain access to decision-making forums and for national organizations to facilitate having nurses participate. One strategy being developed by the AAN expert panel on quality care is to develop a list of "content experts" that can be used by professional nurses' associations.

Another strategy would be to continue to expand the use of the Internet to communicate important initiatives to nurses with suggested strategies for responding to new events. For example, 
appointment of new advisory committees on health issues that omit nursing representation could trigger queries from individual nurses and groups, as well as recommendations of qualified people who could be added to the group. Partnering with lay advocacy groups can also be helpful in gaining access to policy groups.

A third strategy would be for schools of nursing to help faculty identify policy implications of their research, in addition to the clinical applications. A cadre of nurse scientists is needed who can translate their research findings into policy-relevant recommendations. This strategy requires that the policy questions be built into research proposals before their submission. However, health policy recommendations require more than a careful evaluation of scientific evidence of benefits and adverse effects of interventions. Fletcher (1997) points out that policy recommendations also require a thorough evaluation of cost and cost-effectiveness, careful consideration of medicolegal, ethical, and economic implications, and acknowledgment of other health policies that must also be implemented with finite resources.

Nurses must develop the necessary skills to participate fully on interdisciplinary research, administrative, and clinical teams. A challenge for nurses and other disciplines is to be taught to adopt an integrated practice framework that includes nursing, medical, social work, pharmacy, and business perspectives. Kerfoot (1996) recommended an interdisciplinary approach to health professions education. Deans and faculty of the various health professions' schools should be creative in developing appropriate interdisciplinary learning activities.

\section{Identifying Clinical and Management Strategies That are Effective}

A different concern is the lack of validation of many care management strategies before their widespread distribution and adoption. Recently interest in data-driven or evidence-based protocols rather than consensus-driven practice guidelines has developed. Many clinical interventions and therapeutic strategies have been adopted without empirical evidence to support their effectiveness. In nursing, the adoption of critical pathways and case management models has proceeded with inadequate evaluation of their effect on outcomes (Gordner \& Moritz, 1995; Lamb, 1992). Consequently, the link between pathways, case management, and desired organizational and patient outcomes remains vague. Furthermore, studies have not clearly described and measured the intervention being tested. The "dose" of both clinical and organizational interventions needs to be carefully explicated (Brooten \& Naylor, 1995).

Changing the Clinical Framework. The concept of a boundaryless care delivery system must be incorporated into these efforts. An expanded view of outcomes management extends beyond traditional systems and requires redefining an episode of illness as an episode of care. documenting service delivery from point of entry to point of exit. Such a redefinition highlights several measurement needs (Lamb, 1996): for longitudinal measurement of outcomes (immediate, intermediate, and long-term); for adequate case-mix measurement and risk-adjustment; for adequately describing providers of care and interventions; and for including contextual variables.

Demonstrating Nursing's Contributions. A compelling need exists to articulate the relationship of nursing interventions and therapies to clinical conditions and health problems-an important quest because what nurses do is unclear to many. Although this is an age-old issue, the fact remains that data are limited regarding the effects of nursing. 1997 is the time to clarify the effects of nursing. Several classification systems now exist to facilitate this effort (Grobe, 1992; McCloskey \& Bulechek, 1996; McFarland \& McFarlane, 1993; Saba et al., 1991; Saba, 1992).

Also, demonstrating nurses' contribution to interdisciplinary care is vital. Increasingly, health care is being planned and implemented by interdisciplinary teams. With continued expansion of managed care, the best qualified but least expensive practitioner is often the provider of choice. In many cases, that practitioner is a nurse or physician, but in some cases it is an unlicensed worker. Outcome analyses with newly identified indicators and measures, such as those in the ANA Report Card or the Q-HOM, give the opportunity to evaluate the effect of teams on care results (ANA, 1995) taking severity of illness and of risk level into account (Tezzoni, 1994).

The third strategy is a collaborative approach to outcomes analysis. Collaboration in this sense pertains to an interdisciplinary alliance between researchers and expert clinicians to examine the effect of nursing care. Expert clinicians are important to identifying crucial clinical questions. Another aspect of such collaboration is establishing the infrastructure for data on nursing practice. By identifying patient care measures pertinent to nursing, it will be possible to incorporate indicators in the clinical data records that show effects. In many clinical settings, this may mean adding data elements to existing information systems. In other situations, achievement may mean implementing a new data system that includes nursing practice-related information. Several existing software packages for clinical data are useful. In addition, Saba and McCormick (1996) have compiled an overview of computer-related information.

\section{Implications for Practice and Management}

Outcomes analysis requires total organizational commitment, including the commitment of resources and personnel for analysis, application of findings to the development of outcomes management strategies and ongoing follow-up and evaluation. Information obtained through outcomes analysis will be valued by purchasers and providers if it can be linked to tangible benefits, such as reduced costs, early return to work, improved productivity, improved efficiency, reduced variation, and increased patient satisfaction (England, 1996).

Although outcomes studies require funding, in many instances new funds will not be necessary. Various outcomes-based analyses already occur within most U.S. health care institutions and organizations. By bringing together resources and funding, 
a systematic, collaborative outcomes analysis can often be developed with few additional expenditures.

Outcomes analyses can influence health policy and patient decisions. Legislative and nonlegislative initiatives to reform the nation's health care system include provisions for outcomes evaluation. Multiple factors and forces, many of them still emerging, influence the need for meaningful data-based outcome measures. Data bases to support informed clinical decisionmaking are largely nonexistent; yet application of outcomes management principles and methods is proceeding. For example, providers, third-party payers, and employers are already using outcomes data to evaluate and demonstrate quality of care.

Models, methods, and activities are urgently needed to guide management of patient care across the continuum. Development of these guiding principles should occur collaboratively, involving nurses, physicians, and others including patients and families. Only a collaborative approach can ensure affordable high quality outcomes.

Quality is the primary focus of outcomes evaluation. In the current health care delivery environment, the urgency of cost containment might overshadow the importance of quality. In reality, cost and quality are mutually supportive rather than mutually exclusive. Nurses are ideal candidates to conduct systems and patient-oriented outcomes studies and to develop widely applicable principles of outcomes analysis and management.

\section{References}

American Nurses Association. (1995). Nursing report card for acute care settings. Washington, DC: Author.

Anderson, C.A. (1996). Editorial: Underwhelmed and disappointed. Nursing Outlook. 44, 113-114

Brooten, D., \& Naylor, M.D. (1995). Nurses' effect on changing patient outcomes. Image: Journal of Nursing Scholarship, 27, 95-99.

Bryan-Brown, C.W., \& Dracup, K. (1996). Outcomes, endpoints, and expectations. American Journal of Critical Care. 5, 87-89.

Donabedian, A. (1985). The methods and findings of quality assessment and monitoring: An illustrated analysis. Volume 3. Ann Arbor, MI: Health Administration Press.

Ellwood, P. (1988). Shattuck lecture - outcomes management: A technology of patient experience. New England Journal of Medicine, 318, 1549-1556.

England, M.J. (1996). Issues in outcomes measurement in the managed care environment. Presented at AAN Conference on Outcome Measures and Care Delivery Systems, Washington, DC.

Fletcher, S.W. (1997). Whither scientific deliberation in health policy recommendations? New England Journal of Medicine, 336, 1180-1183.

Gordner, R.L., \& Moritz, P. (1995). Critical pathways. (Publication Number: CBM-95-8). USDHHS, NIH, Superintendent of Documents. Washington, DC: U.S. Government Printing Office.

Grobe, S.J. (1992). Nursing interventions lexicon and taxonomy. In K.C. Lun, P. DeGoulet, T.E. Piemme, \& O. Rienhoff (Eds.), MEDINFO '92. (981-986). Amsterdam, Netherlands: North Holland-Elsevier Science Publishers.

Iezzoni, L.I. (1994). Risk adjustment for measuring health outcomes. Ann Arbor, MI: Health Administration Press.

Institute of Medicine. (1996). Nursing staff in hospitals and nursing homes: Is it adequate? Washington, DC: National Academy Press.

Joint Commission for Accreditation of Healthcare Organizations. (1990). The new standards for nursing care. Oakbrook Terrace, IL: Author.

Joint Commission for Accreditation of Healtheare Organizations. (1994). A guide to establishing programs for assessing outcomes in clinical settings. Oakbrook Terrace, IL: Author.

Joint Commission for Accreditation of Healthcare Organizations. (1997). ORYX outcomes: The next evolution in accreditation. Oakbrook Terrace, IL: Author.
Kerfoot, K. (1996). Transprofessional patient care - The nurse manager's challenge. Nursing Economics, 14, 123-125.

Lamb, G.S. (1992). Conceptual and methodological issues in nursing case management research. Advances in Nursing Science, 15, 16-24.

Lamb, G.S. (1996). Outcomes across the care continuum. Presentation at the AAN Conference on Outcome Measures and Care Delivery Systems. Washington, DC.

Lohr, K.N. (1988). Outcome measurement: Concepts and questions. Inquiry, $25,37-50$.

McFarland, G.K., \& McFarlane, E. (1989). Nursing diagnoses and interventions: Planning for patient care. St. Louis, MO: Mosby.

McCloskey, J.C., \& Bulechek, G.M. (Eds.) (1996). Nursing interventions classification (NIC)(2nd ed.). St. Louis, MO: Mosby Yearbook.

Medical Outcomes Trust. (1996a). Bulletin, 4(5), 1.

Medical Outcomes Trust. (1996b). Source pages. Boston: Author.

Medical Outcomes Trust. (1997). Source pages. Boston: Author.

Mitchell, P. (1996). Outcome measures and care delivery systems: Conference summary. Presented at AHCPR Workshop on Nurse Staffing and Quality in Hospitals, Washington, DC.

Saba, V.K., O'Hara, P.A., Zuckerman, A.E., Boondas, J., Levine, E., Oatway, D.M. (1991). A nursing intervention taxonomy for home health care. Nursing and Health Care, 12, 296-299.

Saba, V.K. (1992). The classification of home health care nursing diagnoses and interventions. Caring, 11, 50-57.

Saba, V.K., \& McCormick, K.A. (1996). Essentials of computers for nurses. New York: McGraw-Hill Books.

Schlenker, R.E. (1996). Outcomes across the care continuum: Home health care. Presented at the AAN Conference of Outcome Measures and Care Delivery Systems. Washington, DC.

Shine, K. (1996). From the IOM president. American Health In Transition, 1,2 .

U.S. Congress, Office of Technology Assessment. (1994). Identifying health technologies that work: Strategies for evidence. (OTA Publication No. OTAH-608). Washington, DC: U.S. Government Printing Office.

U.S. General Accounting Office. (1994). Health care reform: "Report Cards" are useful but significant issues need to be addressed. Washington, DC: Author.

Ware, J.E., \& Sherbourne, C.D. (1992). The MOS 36-item short-form health survey (SF-36): Conceptual framework and item selection. Medical Care, 30 , 473-483.

Wennberg, J.E. (1984). Dealing with medical practice variation: A proposal for action. Health Affairs, 3, 6-32.

Wennberg, J.E. (1986). Which rate is right? New England Journal of Medicine, 314, 310-311.

Wojner, A.W. (1996). Outcomes management: An interdisciplinary search for best practices. American Journal of Critical Care, 7, 133-145.

Zelman, W.A. (1996). The changing health care marketplace: Private venture, public interests. San Francisco, CA: Jossey-Bass.

\section{HEALTH POLICY NEW BOOKS \\ "Mortal Peril: Our Inalienable Right To Health Care?" by Richard A. Epstein \\ Reading, MA, Addison-Wesley, 1997, 503 pages.}

"Market Driven Health Care: Who Wins, Who Loses in the Transformation of America's Largest Service Industry" by Regina Herzlinger

Reading, MA, Addison-Wesley, 1997, 379 pages.

"The Future of Long-Term Care: Social and Policy Issues" edited by

Robert H. Binstock, Leighton Cluff, and Otto Von Mering Baltimore, MD, Johns Hopkins University Press, 1996, 300 pages.

"Hazards of the Job:

From Industrial Disease to Environmental Health Science" by Christopher Sellers

Chapel Hill, NC, University of North Carolina Press, 1997, 331 pages. 